\title{
Study of Autogenous Self-Healing in Different Mortar Formulations
}

\author{
Nohelia Gutiérrez, Laia Haurie, Antonia Navarro and Joan Ramon Rosell \\ Universitat Politècnica de Catalunya, Barcelona School of Building Construction, Av. Doctor \\ Marañon 44, 08028 Barcelona, Spain, csn.gutierrez@gmail.com, laia.haurie@upc.edu, \\ antonia.navarro@upc.edu, joan.ramon.rosell@upc.edu
}

\begin{abstract}
Autogenous self-healing of cement-based materials is a topic of current interest. This research evaluates autogenous self-healing in four types of mortars based on Portland Cement, one containing CEM II and the other 3 formulated with CEM I and different additions: fly-ashes; nanosilica and hydraulic lime. The evolution of longitudinal cracks caused by a point load has been evaluated measuring the water absorption by capillarity and studying the evolution of the crack by optical microscopy. Besides the mortar composition, it has been evaluated the effect of the environmental conditions on the crack repair. The different specimens were exposed to three different environments: water immersion, curing chamber at $20 \pm 2{ }^{\circ} \mathrm{C}$ and $95 \pm 5 \%$ of relative humidity (RH) and the laboratory at $25 \pm 5^{\circ} \mathrm{C}$ and $65 \% \pm 5 \% \mathrm{RH}$. The results obtained allow us to establish that constant hydration is an essential factor for the development of self-healing mechanism. If the samples are kept in water immersion self-healing occurs no matter the additions of the mortar formulation. Size of the crack is also an important factor to allow self-healing. The product formed during selfhealing to fill the crack is mainly calcium carbonate.
\end{abstract}

Keywords: Self-Healing, Cement, Environmental Conditions, Cracks, Water Absorption Test.

\section{Introduction}

Currently, several research fields have been dedicated to studying self-healing materials; among these smart materials are cement-based materials. Cracking is inherent to the material, however, the crack width should not exceed a prescribed limit because it can affect its durability and resistance against aggressive substances (Ghosh, 2009).

This research focuses on the autogenous self-healing of the cracks of mortars based on Portland cement at early stages. Autogenous self-healing is a natural phenomenon (Joseph, 2008) and this process mainly relies on chemical, physical and mechanical interactions (Kishi, Ahn, Hosoda, Suzuki, and Takaoka, 2007).

Several authors have demonstrated that the presence of water is fundamental in order to obtain autogenous self-healing. For instance (ter Heide and Schlangen, 2007) concluded that hydration was the mechanism for crack healing that leads to the strength recovery of the prismatic specimens. Similarly (de Rooij, Schlangen, De Belie, and Van Tittelboom, 2011) indicated that one of the two chemical processes for self-healing is the continuous hydration of cement. Regarding the influence of environmental conditions, the investigation of (Argouges, 2012) showed evidence of natural self-healing in cracked specimens stored in a humid environment $23^{\circ} \mathrm{C}$ and $100 \% \mathrm{RH}$, for up to 5 months. The incorporation of cementitious materials is another factor influencing self-healing. The investigations of 
(Huang, Ye, and Damidot, 2014) and (Van Tittelboom, Gruyaert, Rahier, and De Belie, 2012) studied the effect of blast furnace slag and fly-ash on self-healing of cracks in cementitious materials. Likewise, the research of (De Nardi, Cecchi, Ferrara, Benedetti, and Cristofori, 2017) showed that the presence of crystalline admixtures speeds up the sealing of the cracks and the recovery of the mechanical properties. In order to evaluate self-healing ability there are several methods, (Wang, De Belie, and Verstraete, 2012) used the capillary absorption test to show that the specimens had a low water absorption, which indicated that the precipitation inside the cracks increased the water penetration resistance of the cracked specimens. In the same way, (Qureshi, Kanellopoulos, and Al-Tabbaa, 2016) concluded the improvement in terms of capillary absorption of healed samples was significant after 28 days of healing. Microscopic methods had also been used extensively to evaluate both autogenous and autonomous self-healing. The specimens are observed before and after the healing process (Tang, Kardani, and Cui, 2015).

In this study, the effect of different environment conditions on the autogenous self-healing of different Portland mortar admixtures was evaluated by means of the capillary absorption test and by optical microscopy.

\section{Experiment}

\subsection{Materials}

In this study, there were used four mortar formulations based on Portland Cement, one containing CEM II / A-V 42,5 R and the other 3 formulated with CEM 52,5 R and different additions: fly-ash from the Bocamina Thermoelectric Power I la $\mathrm{SiO}_{2}$ content of 99.998 cementitious conglomerate $(\mathrm{s} / \mathrm{c})$ was 3 and it wa ratio $(\mathrm{sp} / \mathrm{c})$ of 0.012 . Table 1 presents the compos ide CL-90. Th were cast in large plastic molds of $100 \times 100 \times 500 \mathrm{~mm}^{3}$ and were reinforced with electro(

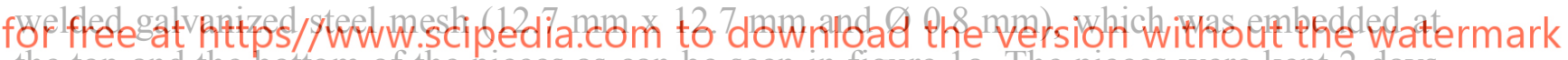
the top and the bottom of the pieces as can be seen in figure $1 \mathrm{a}$. The pieces were kept 2 days in the mold and after demolding were cured 5 days in the curing chamber at $20 \pm 2^{\circ} \mathrm{C}$ and 95 $\pm 5 \%$ of relative humidity $(\mathrm{RH})$. The next day, the pieces were removed from the curing chamber and divided into small specimens of 100x100x40 $\mathrm{mm}^{3}$. Mortar specimens were fabricated to evaluate cracks at very early stages; therefore, at the age of 9-d, longitudinal cracks were caused to the specimens by a point load (figure 1b). The cracking process started with a constant average loading speed and then it was decreased to $0.2 \mathrm{~mm} / \mathrm{s}$.

\subsection{Environmental Exposure}

The effect of the environmental conditions on self-healing of concrete has been previously reported (Suleiman and Nehdi, 2018). Therefore, cracked specimens of the four mortar formulations were exposed for 60 days to 3 different environments: water immersion at laboratory conditions, curing chamber at $20 \pm 2^{\circ} \mathrm{C}$ and $95 \pm 5 \%$ of $\mathrm{RH}$ and the laboratory at $25 \pm 5^{\circ} \mathrm{C}$ and $65 \% \pm 5 \% \mathrm{RH}$. This last group received a weekly amount of water to simulate an environment with the presence of average humidity. 
In addition, in each environmental condition, the specimens were divided into two groups: cracked and control specimens (without cracks). The comparison between both specimens reaffirmed the evolution of the longitudinal cracks.

Table 1. Mix design of the four mortar formulations.

\begin{tabular}{ccccc}
\hline Material (g) & $\begin{array}{c}\text { Formulation } \\
\text { M1 }\end{array}$ & $\begin{array}{c}\text { Formulation } \\
\text { M2 }\end{array}$ & $\begin{array}{c}\text { Formulation } \\
\text { M3 }\end{array}$ & $\begin{array}{c}\text { Formulation } \\
\text { M4 }\end{array}$ \\
\hline CEM II/A-V 42,5 R & 7000 & & & \\
\hline Natural sand & 21000 & 21000 & 21000 & 21000 \\
\hline Water & 3710 & 3850 & 4760 & 4550 \\
\hline Superplasticizer & 84 & 84 & 84 & 84 \\
\hline CEM I 52,5 R & & 5950 & 5950 & 5950 \\
\hline Fly-ash & 1050 & & 525 \\
\hline Nanosilica & & 700 & \\
\hline Filler & & 350 & 525 \\
\hline CL-90 & & &
\end{tabular}

Register for free at https//www.scipedia.com to download the version without the watermark
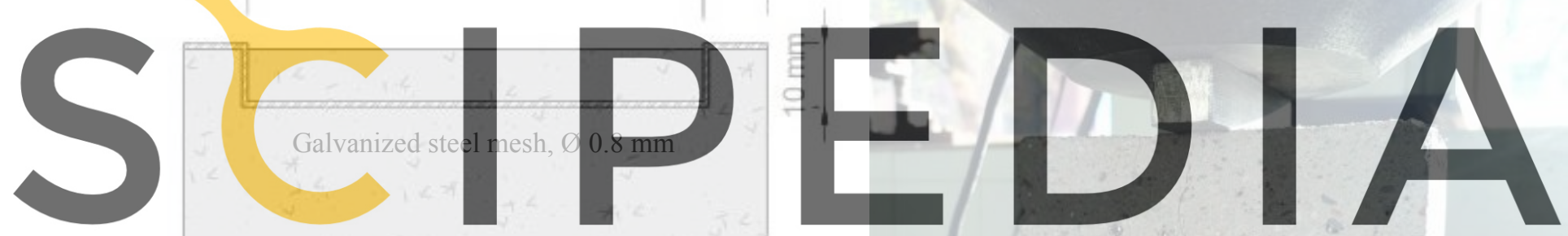

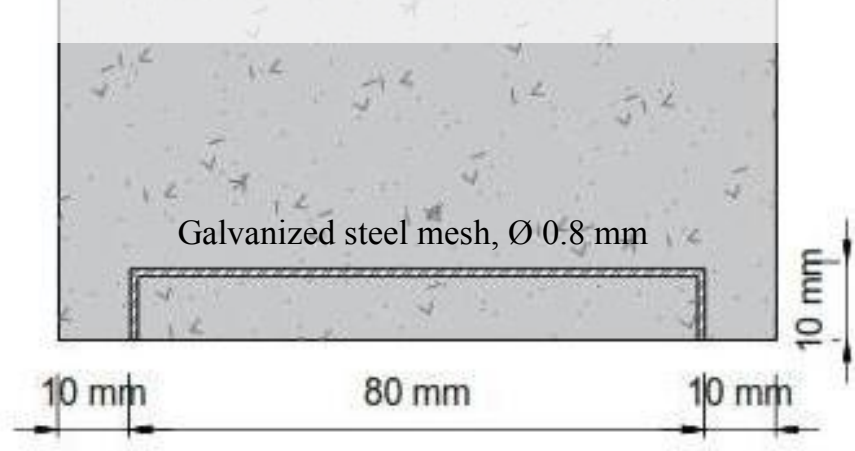

a

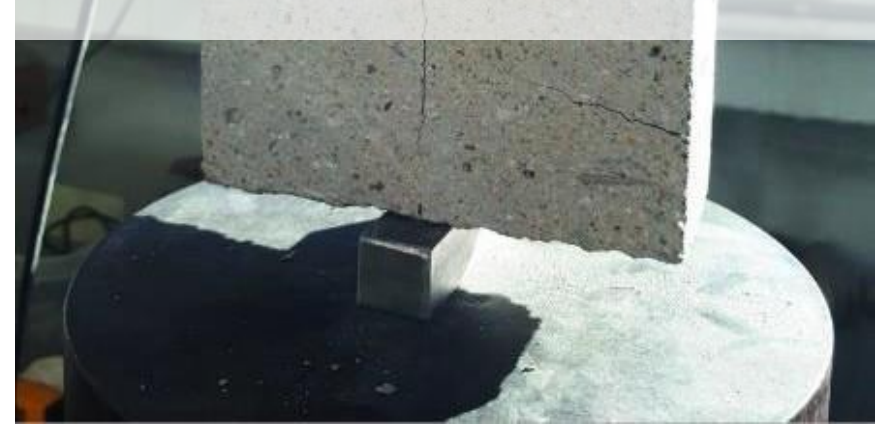

b

Figure 1. (a) Steel mesh scheme and (b) cracking of the specimen by a point load. 


\subsection{Analysis of Self-Healing Products}

\subsubsection{Water absorption test by capillarity}

The water absorption test could effectively evaluate the self-healing performance of cementbased materials (Park and Choi, 2018). This test was performed according to UNE-EN 1925 Natural stone test methods. Determination of water absorption coefficient by capillarity. All 100x100x40 $\mathrm{mm}^{3}$ specimens were oven-dried at $70 \pm 5^{\circ} \mathrm{C}$. The samples were weighted and the bottom surface was measured before they were immersed in water at a depth of $5 \pm 1 \mathrm{~mm}$. The mass of water absorbed by the samples was measured at: 1, 9, 16, 36, 49, 64, 81, 121, 225 and 361 minutes. The test was carried out before cracking, upon cracking and after 7, 15, 30 and 60 days of exposure to the three different environmental conditions.

The mass of water absorbed per square meter was plotted against the square root of time and the water absorption coefficient $(\mathrm{S})$ was determined using linear regressions.

\subsubsection{Self-healing evaluation by opticalmicroscopy}

Optical microscopy was used to observe the cracks surface (Homma, Mihashi, and Nishiwaki, 2009). In this investigation the evolution of the longitudinal cracks surface was monitored just upon cracking, and after 7, 15, 30 and 60 of exposure to the different environments. The device used was a Motic Stereoscopic Microscope with Euromex 10 Megapixel Image Sensor. Each crack was divided into sectors to analyze the evolution of the cracks in each

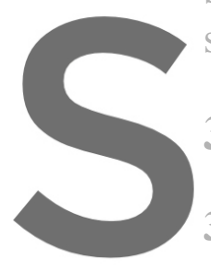
specimen.
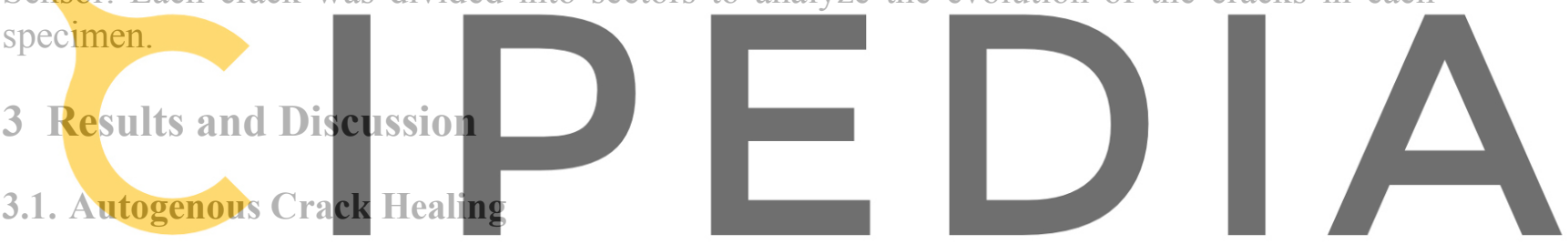

Water absorption test

Register for free at https//www.scipedia.com to download the version without the watermark The results showed the relationship between the self-healing efficiency and the variation of the absorption coefficients over time (before, upon, and after cracking) of the specimens in the three different environmental conditions (immersion, humidity chamber and laboratory). With this information, for each environment and for each mortar formulation, exponential adjustments were made and the mean of the cracked and control (non-cracked) specimens was calculated, as can be seen in figure 2.

A first general observation was that all cracked specimens that were fully immersed in water showed absorption coefficients that decreased over time, this confirmed the crack healing and the formation of hydration products. In the case of cracked specimens exposed to the curing chamber, the absorption coefficients also decreased over time. However, the absorption coefficients were higher than for the immersed samples. This could be due to an incomplete crack healing of the mortars. For cracked specimens conditioned in the laboratory, their absorption coefficients remained almost similar over time and were higher than the aforementioned cases. This was attributed to the absence of crack healing in the specimens conditioned in the laboratory.

Another remarkable observation, were the differences between control and cracked 
specimens. At the beginning of the test just upon cracking, the absorption coefficients of the cracked specimens were always higher than that of the control specimens. However, after 60 days, the absorption coefficients of the cracked specimens that were fully submerged in water were lower or similar than that of control specimens. This observation clearly indicates that a mechanism of self-healing had occurred, and furthermore, the cracks had a major influence on the capillary water absorption of cementitious materials (Van Belleghem, Van Tittelboom, and De Belie, 2018).

The properties of each mortar formulation were part of this investigation, one of the essential characteristics that make a significant impact on water resistance of mortar is porosity and pore structure (Gulbe, Vitina, and Setina, 2017), graphically it was observed the absorption coefficients of the M2 specimens were higher than the other mortar formulations. This fact indicated that at early ages, fly-ash increases the porosity of the mortar, however, it decreased as the age increased (Termkhajornkit, Nawa, Yamashiro, and Saito, 2009). On the other hand, the absorption coefficients of the M3 and M4 specimens were lower than the other mortar formulations. This was because nanosilica diminishes the total volume of accessible pores in cement mortars (Tobón and Kazes, 2008) and the addition of hydrated lime lowered the total porosity of fly-ash cement pastes (Barbhuiya, Gbagbo, Russell, and Basheer, 2009).
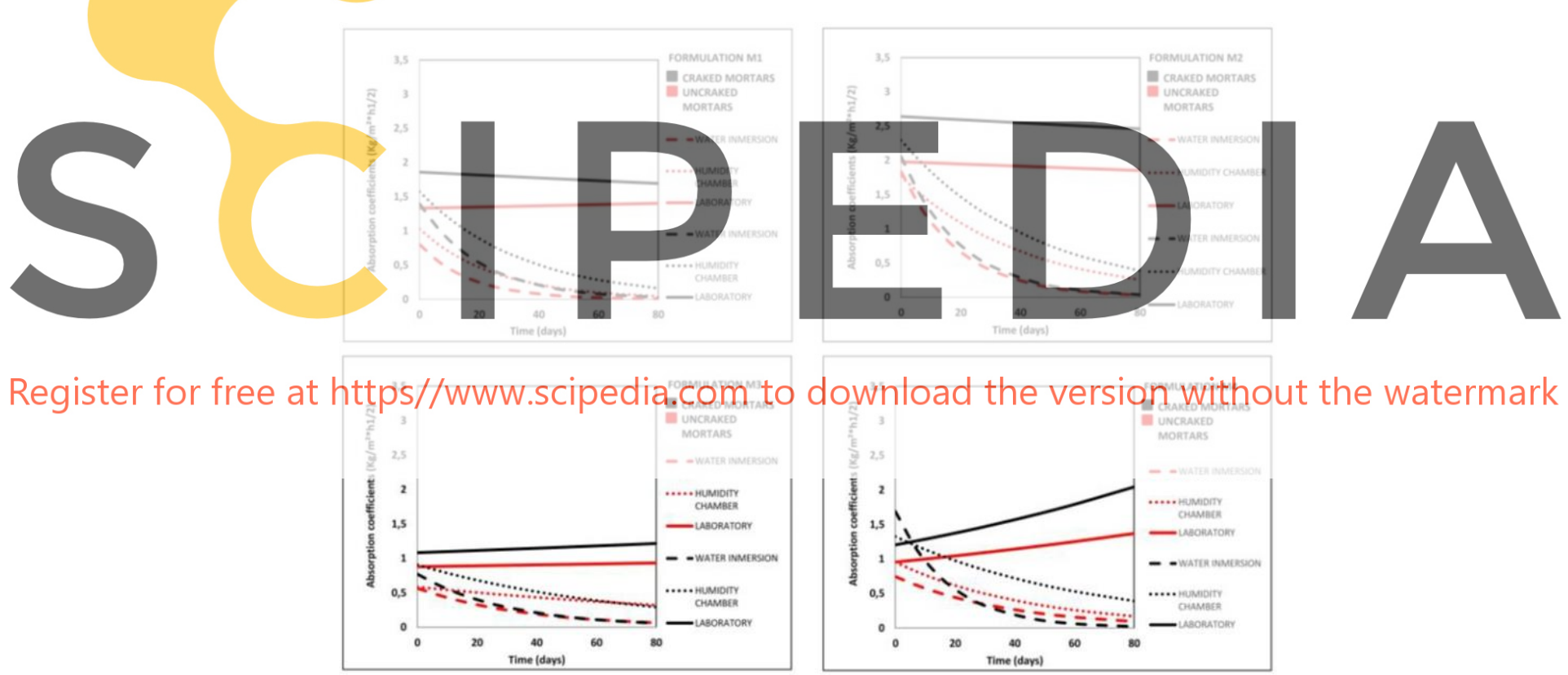

Register for free at https//www.scipedia.com to

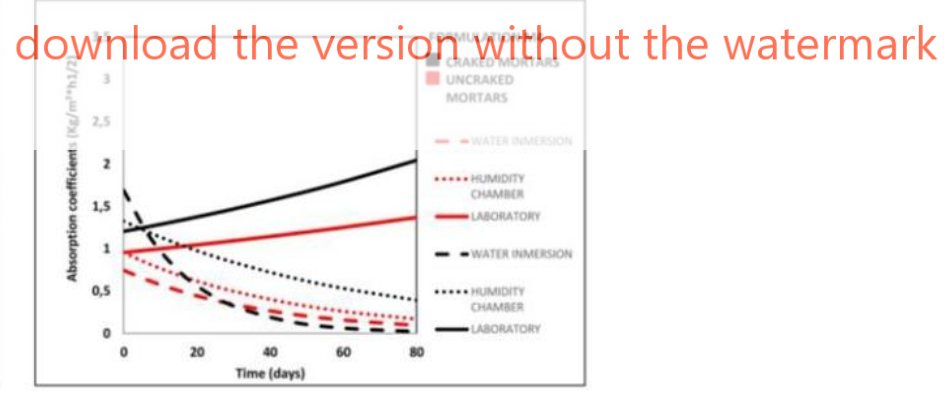

Figure 2. Exponential adjustments that show the variation of the absorption coefficient of the cracked and control specimens exposed to water immersion, humidity chamber and laboratory for a period of 60 days.

\subsubsection{Optical microscopy}

The evolution of the surface crack width of the specimens was measured using a microscope. Four sector images were taken along the crack, before and after the healing 
process. After 60 days, cracks of the specimens immersed in water showed sealing or the formation of healing products along the surface of the crack of the specimens (inside and outside the crack). It must be highlighted that only cracks with a width smaller than $150 \mu \mathrm{m}$ exhibited sealing. The images of the crack evolution can be observed in figure 3 . In the case of the cracks of the specimens exposed to the curing chamber, only in some of the cracks occurred healing. For all the cracks of the specimens conditioned in the laboratory, no evolution or healing products were observed, due to the minimum contact they had with water. These findings were in good agreement with the results of the water absorption test by capillarity.

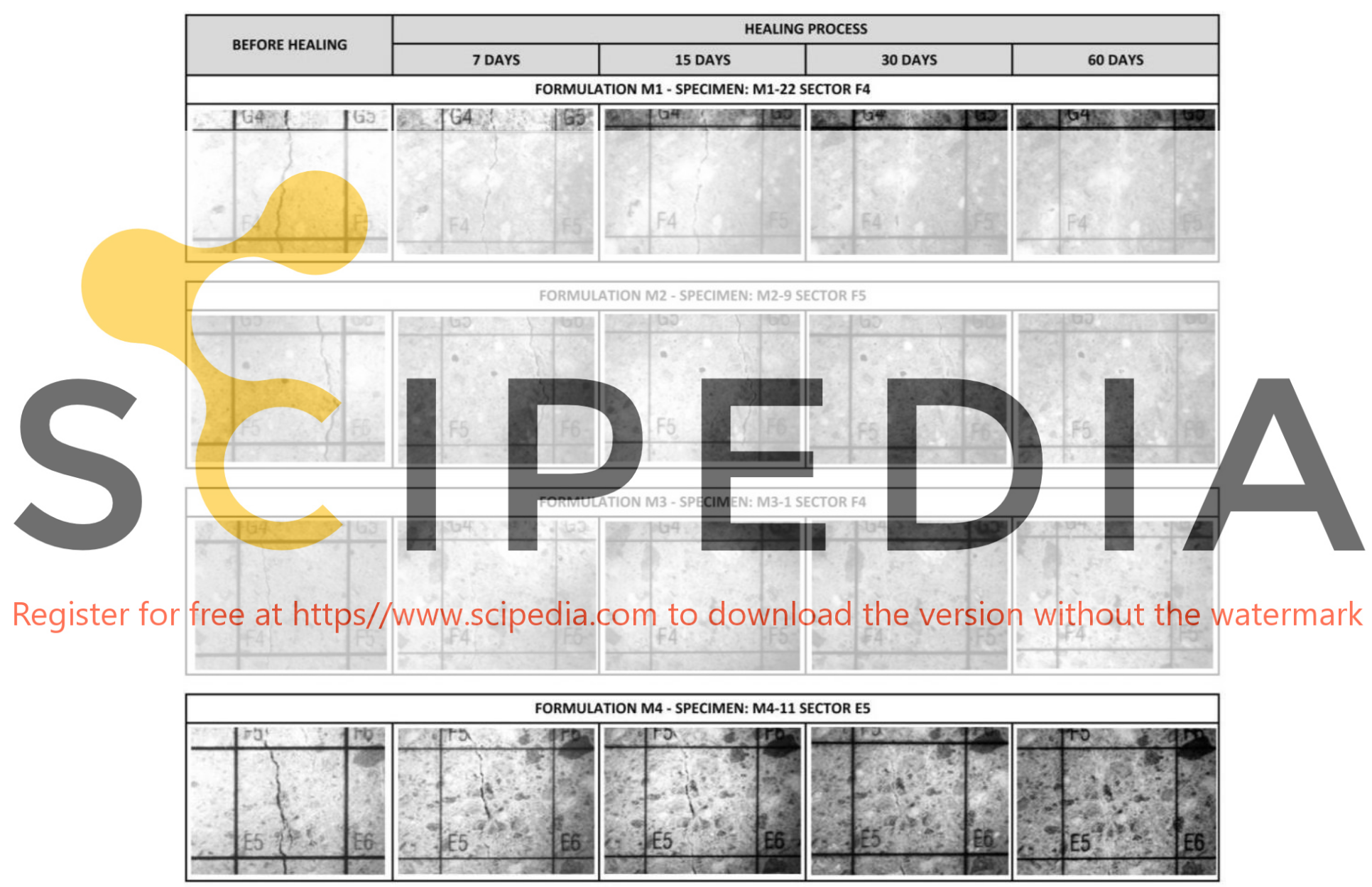

Figure 3. Evolution in the surface crack of different mortar formulations exposed to water immersion. The evolution was analyzed upon cracking and during the healing process.

\section{Conclusions}

This research analyzed the self-healing ability of four mortar formulations of cracked specimens exposed to different environmental conditions. Based on the experiments, the following conclusions were obtained: 
- Constant hydration was an essential factor for the development of the autogenous selfhealing mechanism.

- Width of the crack was an important factor to allow self-healing and from the absorption coefficients could be concluded that wider cracks exhibit higher absorption rates. Nevertheless, the form and path of the cracks were other parameters that had a big influence on self-healing.

- The product formed during self-healing to fill the crack was mainly calcium carbonate.

- The incorporation of additions to cement-based mortars did not influence self-healing of the mortars. In the cracked specimens that were kept in water immersion, selfhealing occurred no matter the additions of the mortar formulation.

- High humidity environment conditions influenced only in some of the cracked specimens, probably in a longer period of exposure, the self-healing of the cracks could be carried out completely.

Although the water absorption test by capillarity measured effectively the self-healing performance of the cracked specimens, in some cases, the evaluation by optical microscopy was more accurate to validate self-healing.

\section{ORCID}

Laia Haurie: http:// orcid.org/0000-0002-0732-8928

Antonia Navarro: http:// orcid.org/0000-0001-6212-8593

Joan Ramon Rosell: http:// orcid.org/ 0000-0001-5034-8388

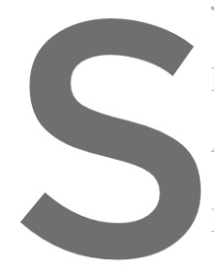

References

Argouges, M. (2012). A s

Structures, 1625-1638.

Barbhuiya, S. A., Gbagb

modified with hydrated

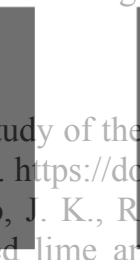

naturalself-healing
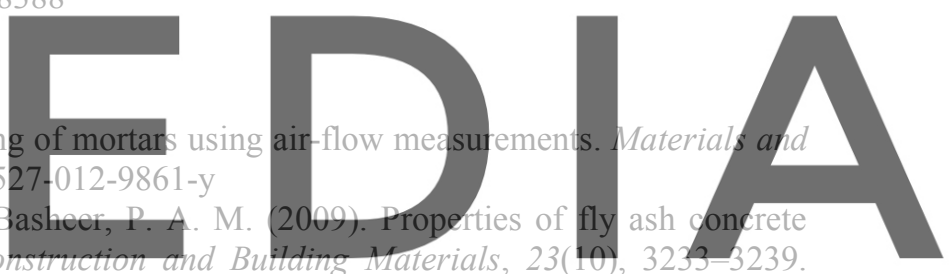

https://doi.org/10.1016/j.conbuildmat.2009.06.001

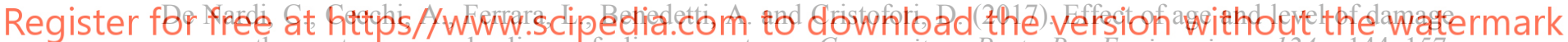
on the autogenous healing of lime mortars.

Guibe, L., Vitina, I. and Setina, J. (2017). The Infiuence of Cement on Properties of Lime Miortars. Procedia Engineering, 172, 325-332. https://doi.org/10.1016/j.proeng.2017.02.030

Homma, D., Mihashi, H. and Nishiwaki, T. (2009). Self-Healing Capability of Fibre Reinforced Cementitious Composites. Journal of Advanced Concrete Technology, 7(2), 217-228. https://doi.org/10.3151/jact.7.217

Huang, H., Ye, G. and Damidot, D. (2014). Effect of blast furnace slag on self-healing of microcracks in cementitious materials. Cement and Concrete Research, 60, 68-82. https://doi.org/10.1016/j.cemconres.2014.03.010

Joseph, C. (2008). Experimental and numerical study of the fracture and self-healing of cementitious materials. Cardiff University, UK.

Kishi, T., Ahn, T., Hosoda, A., Suzuki, S. and Takaoka, H. (2007). Self-Healing Behaviour By Cementitious Recrystallization of Cracked Concrete. First International Conference on Self Healing Materials, (April), 110.

Ghosh, S. K. (2009). Self-healing Materials: Fundamentals, Design Strategies, and Applications. Wiley-VCH Verlag $\mathrm{GmbH}$ and Co. KGaA.

Park, B. and Choi, Y. C. (2018). Quantitative evaluation of crack self-healing in cement-based materials by absorption test. Construction and Building Materials, 184, 1-10. https://doi.org/10.1016/j.conbuildmat.2018.06.206

Qureshi, T. S., Kanellopoulos, A. and Al-Tabbaa, A. (2016). Encapsulation of expansive powder minerals within a concentric glass capsule system for self-healing concrete. Construction and Building Materials, 121, 629643. https://doi.org/10.1016/j.conbuildmat.2016.06.030 
Suleiman, A. R. and Nehdi, M. L. (2018). Effect of environmental exposure on autogenous self-healing of cracked cement-based materials. Cement and Concrete Research, 111 (May), 197-208. https://doi.org/10.1016/j.cemconres.2018.05.009

Tang, W., Kardani, O. and Cui, H. (2015). Robust evaluation of self-healing efficiency in cementitious materials - A review. Construction and Building Materials, 81, 233-247. https://doi.org/10.1016/j.conbuildmat.2015.02.054

Ter Heide, N. and Schlangen, E. (2007). Self healing of early age cracks in concrete. In Proceedings of 1st International Conference on Self Healing Materials, Noordwijk aan Zee, The Netherlands.

Termkhajornkit, P., Nawa, T., Yamashiro, Y. and Saito, T. (2009). Self-healing ability of fly ash-cement systems. Cement and Concrete Composites, 31(3), 195-203. https://doi.org/10.1016/j.cemconcomp.2008.12.009

Tobón, J. I. and Kazes, R. (2008). Desempeño del Cemento Portland adicionado con Calizas de diferentes Grados de Pureza. Dyna, (156), 177-184.

Van Belleghem, B., Van Tittelboom, K. and De Belie, N. (2018). Efficiency of self-healing cementitious materials with encapsulated polyurethane to reduce water ingress through cracks. Materiales de Construcción, 68(330). https://doi.org/10.3989/mc.2018.05917

Van Tittelboom, K., Gruyaert, E., Rahier, H. and De Belie, N. (2012). Influence of mix composition on the extent of autogenous crack healing by continued hydration or calcium carbonate formation. Construction and Building Materials, 37, 349-359. https://doi.org/10.1016/j.conbuildmat.2012.07.026

Wang, J. Y., De Belie, N. and Verstraete, W. (2012). Diatomaceous earth as a protective vehicle for bacteria applied for self-healing concrete. Journal of Industrial Microbiology and Biotechnology, 39(4), 567-577. https://doi.org/10.1007/s10295-011-1037-1
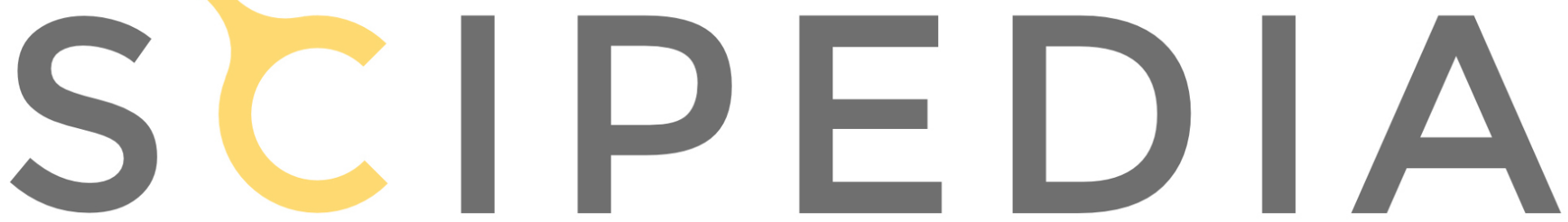

Register for free at https//www.scipedia.com to download the version without the watermark 